\title{
KOMPETENSI DAN KINERJA KARYAWAN BAGIAN PEMASARAN
}

\author{
Nuri Herachwati (herachwati@yahoo.com) \\ Atika Dinita S \\ Fakultas Ekonomi dan Bisnis Universitas Airlangga
}

\begin{abstract}
High competence human resources can support employee performance improvement and contribute in determining the company's future. The aim of this research is to examine and analyze the simultaneous and partial effects of competence characteristics consisting of knowledge and skills, self-concept, and the motives and traits on the performance of employees in the marketing department PT. X. The samples in this study were employees of the marketing department PT. $X$ as many as 42 people, technical analysis is a technique used multiple linear regression analysis. The results found that knowledge and skills, self-concept and motive effect traits Employee Performance in the Marketing Department.
\end{abstract}

Keywords: knowledge and skills, self-concept, motive and traits, employee performance.

\section{PENDAHULUAN}

Boulter, Dalziel dan Hill (1996) mendefinisikan "Kompetensi sebagai karakteristik dasar dari seseorang yang memungkinkan karyawan mengeluarkan kinerja superior dalam pekerjaannya". Kompetensi merupakan bagian kepribadian yang mendalam dan melekat pada seseorang dengan perilaku yang dapat diprediksi pada berbagai keadaan dan tugas pekerjaan. Prediksi siapa yang berkinerja baik dan kurang baik dapat diukur dari kriteria atau standar yang di gunakan.

Menurut Mc. Clelland dalam Cira dan Benjamin (1998), "Dengan mengevaluasi kompetensi yang dimiliki seseorang, kita akan dapat memprediksikan kinerja orang tersebut". Kompetensi dapat digunakan sebagai kriteria utama untuk menilai kinerja seseorang.

Kompetensi knowledge and skills relatif mudah untuk dikembangkan,sehingga program pelatihan merupakan cara yang baik untuk menjamin tingkat kemampuan sumber daya manusia. Sedangkan motive and traits berada pada 'personality iceber ', sehingga salah satu cara yang paling efektif adalah memilih karakteristik tersebut dalam proses seleksi. Oleh karena itu penelitian ini juga menguji masing-masing kompetensi yakni knowledge and skills, self-concept dan motive and traits terhadap kinerja.

Obyek dalan penelitian ini adalah PT. X yaitu perusahaan manufaktur yang bergerak pada bidang industri alas kaki. Sampel penelitian ini bagian pemasaran yang secara umum bertugas untuk melakukan penawaran dan melakukan penjualan kepada konsumen atau agen. Dari hasil penelitian ini diharapkan dapat diketahui seberapa besar kompetensi knowledge and skills, self-concept, motive and traits dapat digunakan untuk meningkatkan kinerja karyawan bagian pemasaran di PT X

\section{LANDASAN TEORI DAN PENGEMBANGAN HIPOTESIS}

Dalam tinjauan pustaka, akan dibahas mengenai pengertian kompetensi, knowledge and skills, self-concept, motive and traits dan kinerja karyawan.

Pengertian Kompetensi

Fokus kompetensi adalah perilaku seseorang karyawan yang dibawa ke dalam pekerjaannya, digunakan untuk melaksanakan tugas dan fungsinya secara efektif.Kompetensi menurut Spencer dan Spencer's (1993) dalam (Seong dan Ji, 2005:260) didefinisikan "sebagai karakteristik internal dari individu yang menghasilkan kinerja efektif dan unggul". Sementara kompetensi menurut Moeheriono (2009:3) "karakteristik yang 
mendasari seseorang berkaitan dengan efektifitas kinerja individu dalam pekerjaannya atau karakteristik dasar individu yang memiliki hubungan kausal atau sebagai sebab akibat dengan kriteria yang dijadikan acuan, efektifitas atau berkinerja prima atau superior ditempat kerja atau pada situasi tertentu".

Berdasarkan dari dua definisi kompetensi diatas, terdapat makna yang terkandunng dalam kompetensi yaitu karakteristik dasar (underlyinng characteristic) dari kepribadian yang mendalam dan melekat pada karyawan serta perilaku yang dapat memprediksi pada berbagai keadaan tugas pekerjaan sehingga karyawan tersebut dapat di tempatkan pada berbagai karakteristik pekerjaan.Kompetensi yang dimilliki oleh seorang karyawan dapat digunakan untukmemprediksikan kinerja karyawan tersebut, artinya jika karyawan tersebut mempunyai kompetensi yang tinggi, maka otomatis karyawan tersebut akan mempunyai kinerja yang tinggi pula (sebagai akibat). Kompetensi yang dimiliki oleh individu dapat juga dijadikan acuan atau memprediksikan seseorang dapat bekerja dengan baik.

Kompetensi karyawan merupakan kompetensi seseorang, yang digambarkan sebagai karakteristik dasar seorang karyawan yang menggunakan bagian kepribadiannya yang paling dalam dan dapat mempengaruhi perilakunya ketika menghadapi pekerjaannya yang pada akhirnya dan berpengaruh pada kemampuannya untuk mengahasilkan kinerja yang baik. Spencer dan Spenser's (1993:179) membagi karakteristik kompetensi menjadi lima kompetensi yaitu sebagai berikut:

1. Motives, yaitu sesuatu dimana seseorang secara konsisten berfikir sehingga karyawan melakukan tindakan.

2. Traits, yaitu watak yang membuat orang untuk berperilaku atau bagaimana seseorang karyawan merespon sesuatu dengan cara tertentu. Misalnya, percaya diri, kontrol diri, atau ketabahan

3. Self-concept, yaitu sikap dan nilai-nilai yang dimiliki seorang karyawan.

4. Knowledge, yaitu informasi yang dimiliki seseorang untuk bidang tertentu. Pengetahuan merupakan kompetensi yang kompleks.

5. Skills, yaitu kemampuan untuk melaksanakan suatu tugas tertentu baik secara fisik maupun mental.

Dalam Penelitian ini variabel yang digunakan sesuai dengan penelitian Seong dan Ji (2005) yaitu knowledge and skills, self-concept, motive and traits, kinerja karyawan

Knowledge dan Skill

Menurut Spencer dan Spencer's (1993:179) "knowledge atau pengetahuan adalah informasi yang dimiliki seseorang untuk bidang tertentu". Pengetahuan merupakan kompetensi yang kompleks. Pendapat lain dikemukakan oleh Judisseno (2008:49), "knowledge what they know adalah sekumpulan informasi dan pengetahuan, misalnya pengetahuan seseorang dalam bidang tertentu".

Skill menurut Spencer dan Spencer's (1993:179) adalah "kemampuan untuk melaksanakan suatu tugas tertentu baik secara fisik maupun mental". Pendapat lain mengenai skill dikemukakan oleh Boulter (1996) "Skill adalah kemampuan untuk melaksanakan suatu tugas dengan baik misalnya seorang programme computer"

Dari beberapa pendapat para ahli di atas dapat diambil kesimpulan bahwa skill adalah kemampuan seseorang untuk menyelesaikan tugas dengan baik dan benar sesuai dengan standar yang ditentukan,baik secara fisik maupun mental. Kompetensi skill dan knowledge cenderung lebih nyata (visible) dan relatif berada di permukaan (ujung) sebagai karakteristik yang dimiliki manusia. 
Penelitian terdahulu yang dilakukan oleh Seong dan Ji (2005) mengemukakan bahwa pengukuran knowledge dan skill sebagai berikut:

1. Aligning Custome,

a. Mengikuti perkembangan.

b. Mencari dan mendapatkan informasi.

2. Engaging in self-appraisal and continious learning, indikatonya adalah:

a. Mencari umpan balik

b. Terus belajar

c. Penerimaan penilaian

\section{Self-Concept}

Judisseno (2008:49) menyatakan "Self Concept adalah konsep pribadi mengenai sikap perilaku, persepsi dan sistem nilai yang kita anut serta percayai dapat menguatkan dan meyakinkan kita sesuai dengan yang kita harapkan". Self Concept dapat menuntun seseorang menjadi orang yang efektif di berbagai lingkungan kerja jika keyakinan tersebut didukung rasa percaya diri yang besar. Sistem nilai yang dianut misalnya tentang kepemimpinan, akan membentuk perilaku menjadi seseorang pemimpin profesional.

Berdasarkan dua pendapat ahli diatas maka dapat disimpulkan Self Concept sebearnya adalah suatu konsep tentang cara seseorang memandang dan menghargai dirinya sendiri serta lingkungan kerjanya yang pada akhirnya dapat menjadi faktor pendukung dalam mengerjakan tugas yang diberikan oleh perusahaan.

Penelitian terdahulu yang dilakukan oleh Seong dan Ji (2005)mengemukakan bahwa pengukuran Self Concept sebagai berikut:

1. Flexibility

a. Kemampuan beradaptasi secara efektif

b. Menghargai masalah

c. Kemampuan beradaptasi memuaskan pelanggan

d. Menerima perubahan pekerjaan

2. Self Confidence

a. Percaya diri menyelesaikan tugas

b. Percaya diri bangkit setelah gagal

3. Self Control

a. Menjaga emosi

b. Kontrol untuk segera bangkit

\section{Motive dan Trait}

Spencer dan Spencer's (1993:179) berpendapat "motive yaitu sesuatu dimana seseorang secara konsisten berpikir sehingga karyawan melakukan tindakan". Pendapat lain dikemukakan oleh Loundon dan Bitta (1993:322) "motive as an inner state that mobilizes bodily energy and direct it in selective fashion toward goals usually located in the external environtment".

Berdasarkan beberapa pendapat di atas maka dapat disimpulkan bahwa motive adalah sesuatu yang dipikirkan oleh seseorang atau suatu dorongan seseorang secara konsisten untuk melakukan suatu tindakan demi tujuan-tujuan yang dicapai. Spencer dan Spencer's (1993:179) berpendapat "Watak yang membuat orang berperilaku atau bagaimana seseorang merespon sesuatu dengan cara tertentu. Misalnya percaya diri, kontrol diri atau ketabahan". Menambahkan bahwa "Traits adalah karakteristik abadi dari seseorang, karakteristik yang membuat orang untuk berperilaku". 
Penelitian terdahulu yang dilakukan oleh Seong dan ji (2005) mengemukakan bahwa pengukuran motive dan traits adalah sebagai berikut:

1. Impact and Influencing

a. Membangun kepercayaan diri

b. Membujuk orang lain

c. Meyakinkan orang lain

d. Mempengaruhi orang lain

e. Membuat terkesan

2. Achievement Orientation

a. Semangat kerja

b. Mempersiapkan diri

3. Analytical Thinking

a. Memahami situasi

b. Membuat kesimpulan

4. Initiative/ Persistence

a. Melebihi harapan

b. Tidak menyerah

5. Problem Solving

a. Mencari sumber masalah

b. Memberikan ide-ide

Kinerja

Kinerja merupakan hasil atau evaluasi dari pelaksanaan kerja karyawan. Bernardin dan Russel (1993) mengukur kinerja dengan:

1. Quality

2. Quantity

3. Timeliness

4. Need for Supervision

5. Interpersonal Impact

Hipotesis dalam penelitian ini adalah ada pengaruh signifikan Karakteristik Kompetensi yang terdiri dari Knowledge and Skills, Self-Concept dan Motive and Traits secara bersama-sama dan parsial terhadap Kinerja karyawan bagian pemasaran PT. X. Dengan kerangka konseptual sebagai berikut:

\section{Gambar 1. Kerangka konseptual}

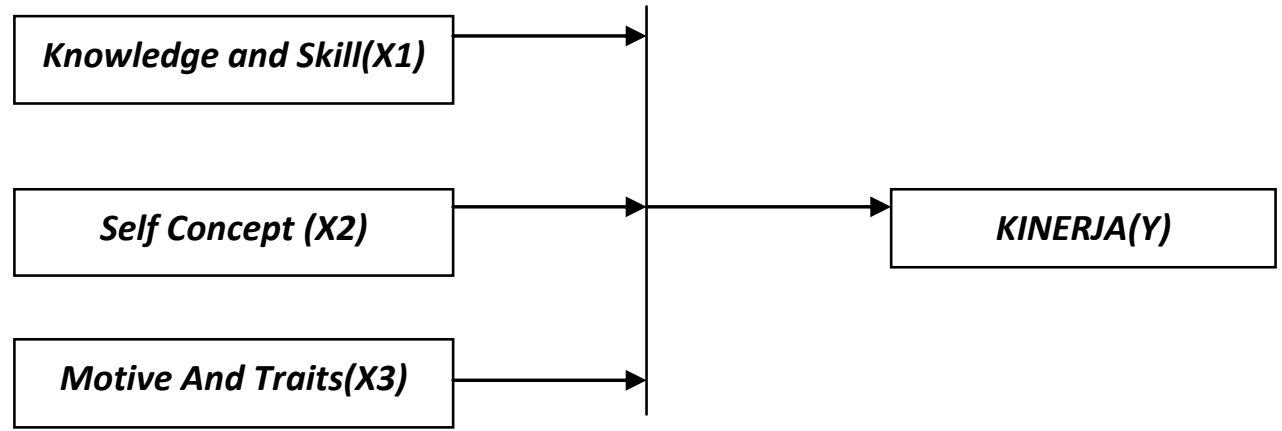




\section{METODE PENELITIAN}

Dalam penelitian ini digunakan pendekatan kuantitatif dengan variabel bebas adalah knowledge and skills (X1), Self-Concept (X2), dan motive and traits (X3) dan variabel terikat adalah kinerja (Y). Teknik analisis yang digunakan dalam penelitian ini adalah is regresi linier berganda dan sampel yang digunakan adalah karyawan bagian pemasaran pada PT. X yang berjumlah 42 orang.

\section{Knowledge and skills $\left(X_{1}\right)$, diukur dengan:}

1. Aligning Customer, kemampuan karyawan bagian pemasaran PT. X untuk:

a. Tetap mengikuti perkembangan yang terjadi pada dunia pemasaran

b. Mencari dan mendapatkan informasi yang dapat menjadi nilai tambahan bagi konsumen.

2. Engaging in self-appraisal and continuous learning, kemampuan karyawan bagian pemasaran PT. X untuk appraisal and continuous learning, kemampuan karyawan bagian pemasaran PT. X untuk:

a. Mencari umpan balik dari konsumen mengenai apa yang diinginkan konsumen.

b. Terus belajar tentang produk yang dihasilkan PT. X.

c. Mau menerima penilaian dari perusahaan dalam rangka pengembangan diri

\section{Self Concept $\left(X_{2}\right)$, dengan indikator}

1. Flexibility. Kemampuan karyawan bagian pemasran PT. X untuk:

a. Beradaptasi den bekerja secara efektif dengan berbagai situasi.

b. Menghargai adanya perbedaan dengan karyawan ketika ada suatu masalah

c. Dapat beradaptasi dengan adanya perubahan yang bertujuan untuk memuaskan pelanggan

d. Menerima perubahan pada perusahaan mengenai pekerjaan itu sendiri

2. Self-Confidence, keyakinan karyawan bagian pemasaran PT. X untuk:

a. Menyelesaikan tugas yang diberikan oleh perusahaan

b. Optimis ketika mengalami kegagalan mengerjakan tujuan yang di berikan perusahaan.

3. Self-Control, Kemampuan karyawan bagian pemasaran PT. X untuk:

a. Menjaga emosi ketika menghadapi masalah

b. Tidak berlarut-larut dalam menghadapi masalah seperti halnya ketika mendapat komplain dari pelanggan

C.

3. Motive and Traits $\left(X_{3}\right)$ diukur dengan:

1. Impact and Influencing, kemampuan karyawan bagian pemasaran PT. X untuk:

a. Membangun kepercayaan dari orang lain agar tujuan yang diinginkan tercapai.

b. Membujuk orang lain agar tujuan yang diinginkan tercapai.

c. Meyakinkan orang lain agar tujuan yang diinginkan tercapai.

d. Kemampuan karyawan bagian pemasaran PT. $X$ untuk mempengaruhi orang lain agar tujuan yang diinginkan tercapai.

e. Kemampuan karyawan bagian pemasaran PT. X untuk membuat orang lain terkesan agar tujuan yang diinginkan tercapai.

2. Achievement Orientation, kemampuan karyawan bagian pemasaran PT. X untuk

a. Menunjukkan semangat dalam bekerja dan bersaing dengan yang lainnya

b. Bertindak mempersiapkan diri sendiri untuk menghadapi tantangan di perusahaan kedepannya 
3. Analytical Thinking, kemampuan karyawan bagian pemasaran PT. X untuk

a. Memahami situasi yang ada pada perusahaan.

b. Membuat kesimpulan dari sebuah permasalahan.

4. Initiative/ Persistence, kemampuan karyawan bagian pemasaran PT. X untuk

a. Melakukan pekerjaan melebihi apa yanng diharapkan oleh perusahaan.

b. Tidak menyrah ketika menghadapi hambatan dalam tugas yang di berikan oleh perusahaan.

5. Problem Solving kemampuan karyawan bagian pemasaran PT. X untuk

a. Mencari sumber dari permasalahan dan memberikan solusi terhadap permasalahan yang terjadi di perusahaan.

b. Memberikan ide-ide atau pendapat yang dapat meningkatkan kinerja perusahaan

\section{Kinerja karyawan ( $Y$ ), diukur dengan:}

1. Quality, merupakan kualitas pelayanan yang diberikan oleh karyawan bagian pemasan PT. X terhadap para pelanggannya

2. Quantity, merupakan jumlah yang dihasilkan, misalnya jumlah rupiah, jumlah unit, jumlah siklus kegiatan yang diselesaikan.

3. Timeliness, merupakan pendapat seorang atasan mengenai kemampuan karyawan bagian pemasaran PT. X dalam melakukan penjualan dalam waktu yang ditentukan.

4. Need for Supervision, merupakan pendapat atasan mengenai kemampuan seorang karyawan bagian pemasaran PT. X untuk dapat melaksanakan suatu pekerjaan tanpa memerlukan suatu pengawasan supervisor untuk mencegah tindakan yang kurang diinginkan.

5. Interpersonal Impact, merupakan pendapat atasan mengenai kemampuan karyawan bagian pemasaran PT. X untuk memelihara harga dir, nama baik dan kemampuan bekerja sama diantara rekan kerja dan bawahan.

Pengukuran untuk indikator-indikator pada penelitian ini digunakan skala pengukuran Likert, Sangat Setuju (5), Setuju (4), Netral (3), Sangat Tidak Setuju (1).

\section{HASIL DAN PEMBAHASAN}

Hasil penelitian menunjukan bahwa Knowledge And Skills (X1), Self-Concept (X2), dan Motive and Traits (X3) berpengaruh significan secara simultan terhadap kinerja karyawan (Y), tampak pada Tabel 4.1 dan Tabel 4.2. Hasil penelitian ini menunjukan bahwa Knowledge and Skills, Self-Concept, dan Motive And Traits yang merupakan komponen dari kompetensi berpengaruh terhadap kinerja karyawan. Karyawan yang memiliki kompetensi yang baik akan mendukungnya dalam mengerjakan tugas dan tanggung jawab yang diberikan kepadanya, kompetensi yang dimiliki karyawan dapat berupa pengetahuan karyawan akan bidang yang dikerjakan atau karakteristik dalam diri individu yang dapat menunjang kinerja individu.

TABEL 1. Hasil Uji F

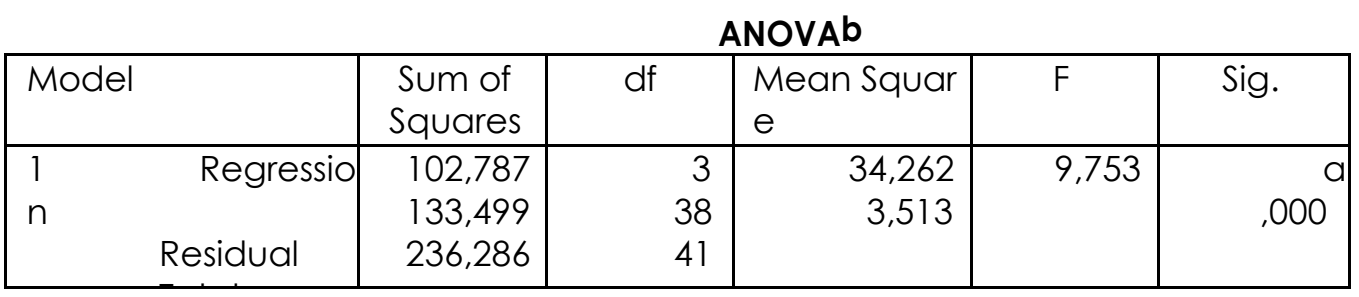


Tabel 2. Besarnya Pengaruh Knowledge And Skills (X1), Self-Concept (X2), dan Motive And Traits (X3) terhadap Kinerja Karyawan (Y) Secara Simultan

\begin{tabular}{|c|c|c|c|c|}
\hline \multicolumn{5}{|c|}{ Model Summaryb } \\
\hline Model & $R$ & R Square & $\begin{array}{l}\text { Adjusted } \\
\text { R Square }\end{array}$ & $\begin{array}{l}\text { Std. Error of } \\
\text { the Estimate }\end{array}$ \\
\hline 1 & $a$ & 435 & ,390 & 1,874 \\
\hline
\end{tabular}

Kompetensi yang dimiliki oleh seseorang akan menyebabkan atau digunakan untuk memprediksikan kinerja seseorang, artinya jika mempunyai kompetensi yang tinggi, maka akan mempunyai kinerja yang tinggi pula (sebagai akibat). Kompetensi yang dimiliki oleh individu dapat juga dijadikan acuan atau memprediksikan seseorang dapat bekerja dengan baik, harus terukur dan spesifik atau terstandar. Seperti yang dikatakan Spencer (1993) bahwa kompetensi merupakan "karakteristik internal dari individu yang menghasilkan kinerja yang efektif dan unggul". Hasil penelitian ini sesuai dengan yang dilakukan oleh Hong (2005) yang menyatakan bahwa knowledge and skills, self-concept,dan motive and traits secara simultan berpengaruh terhadap kinerja karyawan.

Tabel 3. Hasil Uji †

\section{Coefficientsa}

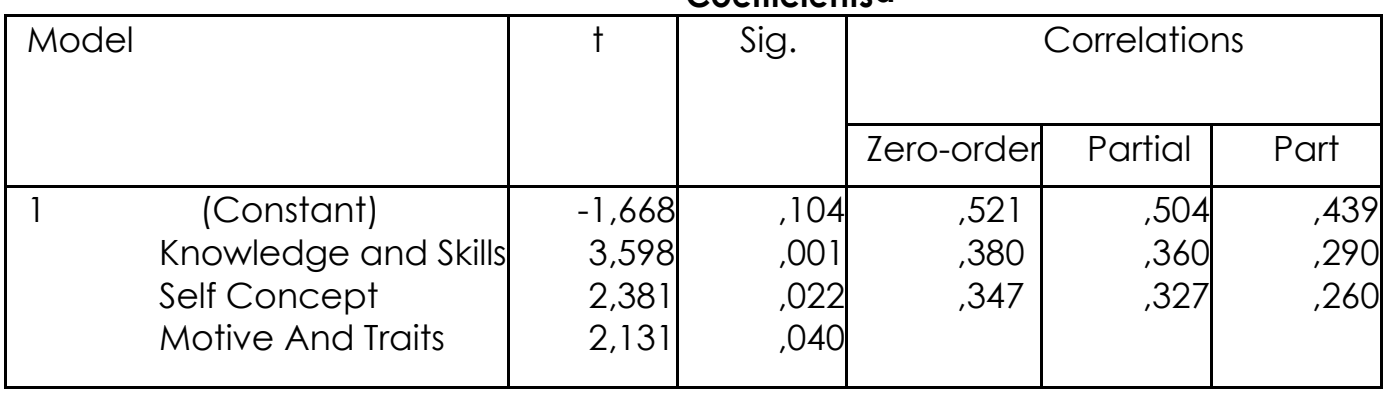

Hasil penelitian ini yang menjelaskan knowledge and skills (X1)berpengaruh positif signifikan terhadap kinerja karyawan (Tabel 4.3), hal ini menunjukkan bahwa semakin karyawan memiliki pengetahuan dan informasi mengenai tugas yang diberikan perusahaan seperti halnya kemampuan karyawan untuk mendapatkan informasi yang diperlukan untuk mempermudah mengerjakan tugas yang di berikan perusahaan dan mau untuk menerima tambahan informasi maka akan membuat kinerja karyawan tersebut semakin baik. Knowledge and skills yang dimiliki karyawan PT X telah cukup baik, artinya dengan pengetahuan dan ketrampilan yang dimiliki karyawan telah mampu menyelaraskan diri dengan pelanggan dan mampu menggali informasi mengenai apa yang di butuhkan pelanggan serta mau untuk terus melakukan pembelajaran berkelanjutan agar ketrampilan dan pengetahuan yang dimiliki dapat terus berkembang.

Hasil penelitian ini yang menyatakan bahwa self-concept (X2) berpengaruh positif signifikan terhadap kinerja karyawan hal ini menunjukkan bahwa semakin karyawan memiliki sikap dan keyakinan dalam mengerjakan tugas yang diberikan perusahaan seperti halnya kemampuan karyawan untuk bekerja secara efektif dalam setiap tugas yang diberikan perusahaan, kemampuan karyawan untuk menghargai adanya perbedaan dengan karyawan dan memiliki keyakinan untuk mengerjakan tugas yang diberikan perusahaan maka akan semakin meningkat hasil kerja dari karyawan tersebut. Secara keseluruhan karakteristik kompetensi self concept yang dimiliki karyawan PT X telah baik hal ini dapat dilihat dari fleksibilitas karyawan yang baik, karyawan mampu beradaptasi dengan perubahan yang terjadi pada perubahan perusahaan maka agar tercipta karyawan yang berkualitas dan mampu beradaptasi dengan perkembangan zaman, PT X mengelola 
karyawan secara profesional agar terwujud keseimbangan antara kebutuhan karyawan dengan tuntutan dan kemampuan perusahaan. Keseimbangan tersebut merupakan kunci vama bagi PT $X$ agar dapat berkembang secara produktif. Karena perkembangan perusahaan sangatlah bergantung pada produktifitas tenaga kerja yang ada di perusahaan. Kepercayaan diri yang baik juga dimiliki oleh karyawan untuk mengerjakan setiap tugas dan tanggung jawab yang di berikan perusahaan, karyawan PT X juga memiliki kontrol diri yang baik seperti halnya mampu untuk menjaga emosi ketika ada permasalahan dan tetap semangat walaupun mendapat keluhan dari pelanggan, sikap percaya diri pada pekerjaan adalah awal menuju prestasi puncak. Sikap percaya diri akan mampu menghapus perasaan takut dan ragu terhadap tugas dan tanggung jawab

Penelitian ini menemukan bahwa motive and traits (X3) berpengaruh positif signifikan terhadap kinerja karyawan, hal ini menunjukkan bahwa semakin karyawan memiliki karakteristik yang mendorong karyawan untuk merespon segala perubahan yang terjadi pada perusahaan seperti halnya kemauan karyawan untuk menunjukkan semangat dalam bekerja dan bersaing dengan karyawan yang lain atau kemampuan karyawan untuk mau mencari sumber dari permasalahan dan memberikan solusi terhadap permasalahan yang terjadi di perusahaan maka hasil kerja yang di capai karyawan akan semakin baik secara kualitas maupun kuantitas dalam perusahaan. Secara keseluruhan karakteristik kompetensi motive and traits yang dimiliki karyawan PT X telah baik hal ini dapat dilihat dari inisiatif yang dimiliki oleh karyawan PT $X$ dan serta karyawan mampu berfikir analistis terhadap permasalahan yang terjadi pada prusahaan serta mampu untuk membantu memecahkan masalah yang terjadi pada perusahaan dan memberikan pendapat atau ide untuk mengatasinya.

\section{DAFTAR PUSTAKA}

Amstrong, Michael.1998, Manajemen Sumber Daya Manusia Alih Bahasa. Syofyan Cikmat dan Haryono. Jakarta : elex media komputindo.

Bernardin , Russel. 1993. Human Resource Management, An Experiental Approach International ,Edition ,Mc Grow - Hill.

Boulter, N, Dalziel, M dan Hill. J ,1996, People and Competencies ,Bidlles,Ltd. London.

Cira D.J. \& Benjamin E.R, 1998 'Competency - Based Pay : A Concept in Evolution'. Compensation and Benefits Review, Agustus Juni.

Ghozali, Imam. 2001 . Aplikasi Analisis Multivariate Dengan Program SPSS. Semarang : Badan Penerbit Universitas Diponegoro

Indrawati. 2006, Faktor-Faktor Yang Mempengaruhi Kinerja Guru Matematika Dalam Pelaksanaan Kurikulum Berbasis Kompetensi Di Sekolah Menengah Atas Kota Palembang, Jurnal Manajemen dan Bisnis Sriwijaya vol. 4 Juni 2006

Judisseno, R.K. 2008, Jadilah Pribadi Yang Kompeten Di Tempat Kerja, Jakarta : PT Gramedia Pustaka Utama.

Mangkunegara, Prabu. 2002. Manajemen Sumber Daya Manusia Perusahaan. Bandung: PT Remaja Rosdakarya.

Mathis R.L dan Jackson J.H. 2002. Manajemen Sumber Daya Manusia, Salemba Empat. Jakarta.

Moeheriono . 2009. Pengukuran Kinerja Berbasis Kompetensi, Penerbit Ghalia Indonesia. 
Salman, 2010 . Pengaruh Kompetens Terhadap Kinerja Dengan Moderasi Self Efficacy Pada Instruktur (Kelompok Jabatan Fungsional) Pusdiklat Migas Cepu. Surabaya.

Sekaran, U. 2006. Metode Penelitian Untuk Bisnis 1. Jakarta: Salemba Empat

Seong Kook Kim \& Ji-Sook Hong. 2005 . The Relationship Between Salesperson Competencies And Performance In The Korean Pharmacutical. Management Reveu vol 16 issue 2

Spencer, L.M./ Spencer, S.M. 1993. Competence At Work. New York : John Willey.

Spencer, M. Lely \& Signe. 1993, Competence At Work, Models for Superior Performance John Wiley \& Sons Inc

Suhartini. 2009, Pengaruh Faktor-Faktor Kompetensi Sumber Daya Manusia Terhadap Kinerja Karyawan .Yogyakarta.

Sulastri, Norma .2010. Pengaruh Kompetensi Karyawan Terhadap Produktifitas Kerja Karyawan Pada PT Jamsostek (Persero) Cabang Medan. Medan . 